\title{
EFFECT OF GASKET OF VARYING THICKNESS ON SPARK IGNITION ENGINES
}

\author{
K. T. AJAYI AND S. O. ABUDU \\ (Received 15, October 2009; Revision Accepted 10, March 2010)
}

\begin{abstract}
In the study of Toyota, In-line, 4 cylinders, spark ignition engine using gaskets of varying thicknesses $(1.75 \mathrm{~mm}, 3.5 \mathrm{~mm}, 5.25 \mathrm{~mm}, 7 \mathrm{~mm}$ and $8.75 \mathrm{~mm})$ between the cylinder head and the engine block, the performance characteristics of the engine was investigated via the effect of engine speed on brake power, brake thermal efficiency, volumetric efficiency and exhaust temperature. To evaluate the performance characteristics for definite gasket (GK) thickness, the engine was operated between $200-4000 \mathrm{rpm}$, under steady state condition. The investigation reveals worsening engine performance with increasing gasket thickness though with improved volumetric efficiency for any given speed range.
\end{abstract}

KEYWORDS: Brake thermal efficiency, volumetric efficiency, Exhaust temperature

\section{INTRODUCTION}

Gaskets have wide industrial applications, such as, in automobile engines. In spite of the fact that the top surface of an engine cylinder block and the lower surface of an engine cylinder head may be smooth to the eye, the two surfaces never fit together closely enough to prevent leakage. Therefore, a gasket must be inserted between them to effect a seal. Various head gasket designs are in use, and these include metal head gaskets, fibrous head gaskets, sandwich type head gaskets having a metallic core and asbestos-bonded layers laminated to the core, chemical formulations containing polytetrafluorothylene, silicone, nitriles, neoprene, polymeric resins etc. Sandwich-type gasket assemblies have sufficient resiliency to seal the cylinder head and sufficient heat resistance, especially when armored, to withstand the high temperature and pressure of the combustion chamber. Nunney (1998) affirmed that asbestos gaskets are becoming increasingly rare due to health concerns.

The gasket must seal against air, coolants, combustion and engine oil at their respective peak operating temperature and pressure and must be able to withstand the dynamic and thermal forces that are transmitted from the head and block, hence sharing the same strength requirements as other combustion chamber components as presented by Bickford (1997). The materials used and design employed must be thermally and chemically resistant to the products of combustion and the various chemicals, coolants and oils used in the engine, therefore avoiding a variety of problems that may occur, ranging from compression loss, which leads to power reduction or rough engine, to exhaust gases being forced into the cooling system, leading to engine overheat and increased engine wear due to the mixing of motor oil with antifreeze.
Furthermore coolant can leak into the cylinders, causing the exhaust to issue steam as revealed by Nunney, (1998), hence damaging the catalytic converter. If a very large amount of coolant does this, hydro-lock may occur, causing extensive engine damage.

Past studies of spark ignition engine were mostly centered on combustion systems as presented by Liberman (2008), Morel and others (1981), while Karlowitz (1974) revealed those centered on emissions control. Those that showed the fuel property effects on combustion and emissions were investigated by Johnson (2005), Kataoka and others (1993), Kahraman and others (2009), Blackmore and Thomas (1977), Owen and Colen (1990), while the works of Hosseini and others (2008), Nunney (1974) centered on engine and component designs. Eastwood (2000), Maus and others (1999) investigated the after-treatment devices in contrast to the engine control study of Kunihiko and others (2005), while Daniels and Braun (2006), Skjoedt and others (2008) systematically investigated the engine tribology. This experimental study, therefore, is a step further in establishing the influence of gasket thickness on brake power, brake thermal efficiency, volumetric efficiency and exhaust temperature for specific speed range of the engine.

\section{EXPERIMENTAL METHODOLOGY}

The experiment was conducted using a four-cylinder engine manufactured by Toyota with the specifications given in Table 1 . The engine with all the necessary accessories, such as, fuel pump, oil sump, exhaust manifold, ignition coil, fan, fan belt, air cleaner, carburetor, etc was solidly mounted on a test rig. A systematic diagram illustrating the experimental layout of the engine is given in Figure 1.

K. T. Ajayi, Department of Mechanical Engineering, University of Lagos, Akoka, Yaba, Lagos, Nigeria

S. O. Abudu, Department of Mechanical Engineering, University of Lagos, Akoka, Yaba, Lagos, Nigeria 
With all the necessary accessories on the engine fitted firmly, the cooling system (radiator) was connected to the engine through water hose with water as the coolant. The inlet and outlet water hose together with the exhaust pipe were perforated in circular shape, so as, to accommodate the temperature sensor (thermometers) necessary for reading the temperatures of the cooling water and the exhaust gas.

Table 1: Engine Specification

\begin{tabular}{ll}
\hline Engine & Specification \\
\hline Manufacturer & Toyota Motor Corporation \\
Model & $4 \mathrm{~K}$, In line, 4 Cylinder, OHV \\
Type & Spark ignition \\
Capacity $(\mathrm{cc})$ & 1,290 \\
Bore x stroke $(\mathrm{mm})$ & $75 \times 73$ \\
Cylinder number & 4 \\
Maximum power $(\mathrm{kW})$ & 86 \\
Maximum torque & $12.7 \mathrm{kgfcm}$ \\
Compression ratio & $9: 1$ \\
Compression Pressure $(\mathrm{kPa})$ & 1,180 \\
\hline
\end{tabular}

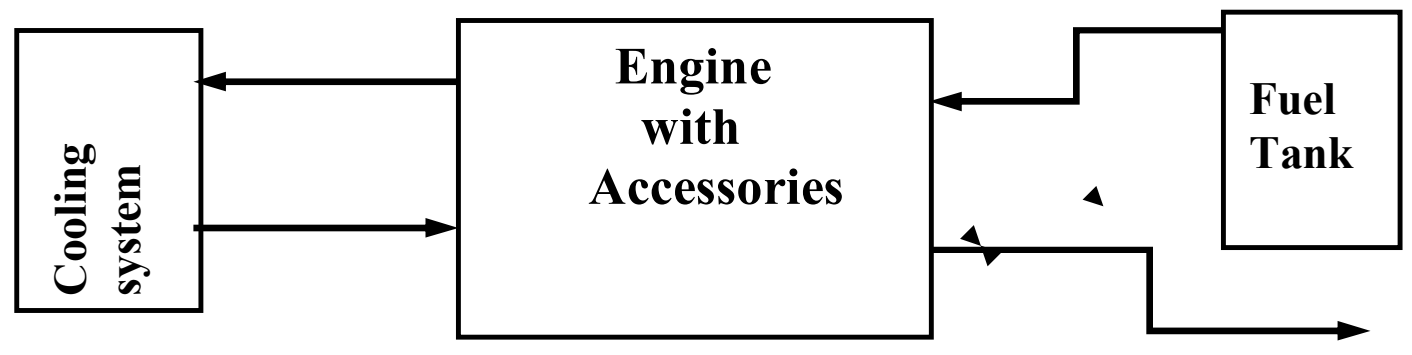

Exhaust

Figure 1: Experimental Layout

Another component specially constructed for this experiment is the fuel system (tank) having a volume of $16.8 \mathrm{~cm} \times 10.5 \mathrm{~cm} \times 20 \mathrm{~cm}$, connected to the engine with fuel solenoid in place to cut off fuel supply when necessary. Furthermore, the fuel tank had necessary arrangement in place to record the mass flow rate of the fuel at any given time. With exhaust manifold properly fixed and the extension directed well away from the setup, the influence of the product of combustion on the experiment was minimized. To ensure close to stoichiometric air/fuel mixture, the air was properly filtered through the air cleaner before mixing with the supplied fuel to the carburetor and finally into the combustion chamber.

Before running the engine, a 4 liter SEA 40 oil lubricant, for effective lubrication of the engine parts, was poured in the oil sump to gauge and new oil filter, plugs, fuel pump and a 64 Ah battery fitted and then, 'test-run' for about 20 minutes to ensure proper connection and functionality of all the components. The engine with $1,75 \mathrm{~mm}$ gasket was then set at $200 \mathrm{rpm}$ and allowed to run for 5 minutes followed by the readings of the water inlet, outlet exhaust temperatures and the mass flow rate of the fuel $\left(m_{f}\right)$. Further readings were taken by varying the speed of the engine at intervals of $200 \mathrm{rpm}$ up to a maximum of $4000 \mathrm{rpm}$. The same procedure was repeated for gasket thicknesses of $3.5 \mathrm{~mm}, 5.25 \mathrm{~mm}$, $7 \mathrm{~mm}$ and $8.25 \mathrm{~mm}$.
From the dimension of the fuel tank, the volume flowrate $\left(\mathrm{V}_{\mathrm{f}}\right)$, hence mass flow rate $\left(\mathrm{m}_{\mathrm{f}}=\rho_{f} \mathrm{~V}_{\mathrm{f}}\right)$, of the fuel was computed at any given time interval $(\Delta \mathrm{t})$. The brake power (BP), brake thermal efficiency $\left(\eta_{b}\right)$ and volumetric efficiency $\left(\eta_{v}\right)$ were then evaluated using standard expressions of Nunney (1974).

\section{DISCUSSION OF RESULTS}

As shown in Figure 2, the brake power is directly proportional to the speed of the engine with slight increase in the constant of proportionality with increasing gasket thickness, which implies that for any given speed, there is increase in the brake power for increasing gasket thickness. The corresponding adverse effect of this phenomenon is represented in Figure 3, where the superiority of the normal $(1.75 \mathrm{~mm})$ gasket with higher brake thermal efficiency for any given speed is clearly illustrated. For all tested head gaskets, the brake thermal efficiency decreases with increasing engine speed, which implies that less mass flow-rate of fuel is required to run the engine with $1.75 \mathrm{~mm}$ gasket.

Because volumetric efficiency is the ratio of air induced, measured at the free air condition to the swept volume of the cylinder and given that the swept volume is virtually the same for all the tested head gaskets, the volumetric efficiency of the engine with $1.75 \mathrm{~mm}$ gasket should be less for any given engine speed due to the 
increase in volume of air induced with increasing gasket thickness, as illustrated in Figure 4. The figure also shows continuous increase in volumetric efficiency with increasing engine speed for any given head gasket. As represented in Figure 5, the exhaust temperature is seen to vary almost linearly with the engine speed for the $1.75 \mathrm{~mm}$ head gasket. Furthermore, the figure also represents the departure from linearity for increasing gasket thickness, which is an indication of the possible difficulties associated with the use of gaskets with thicker material.

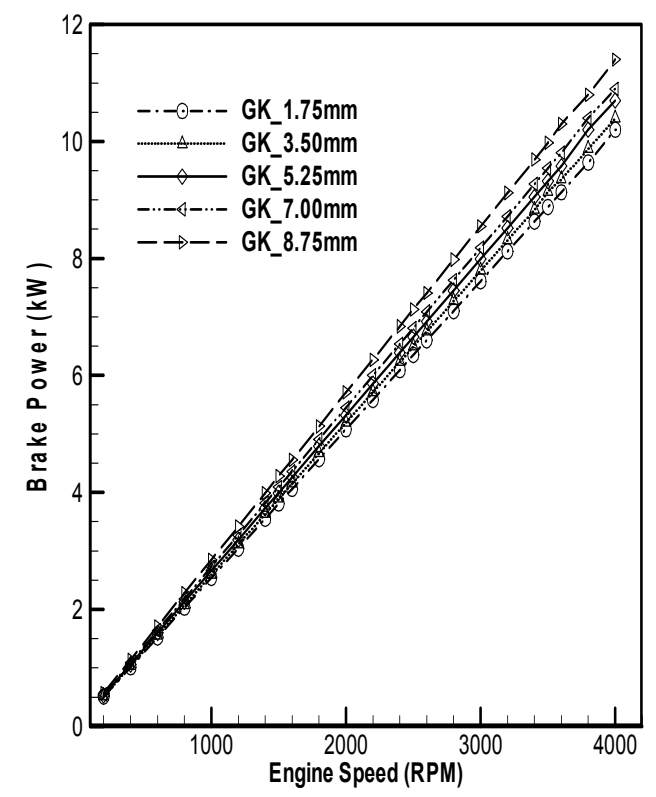

Figure 2: Effect of Speed on Brake Power.

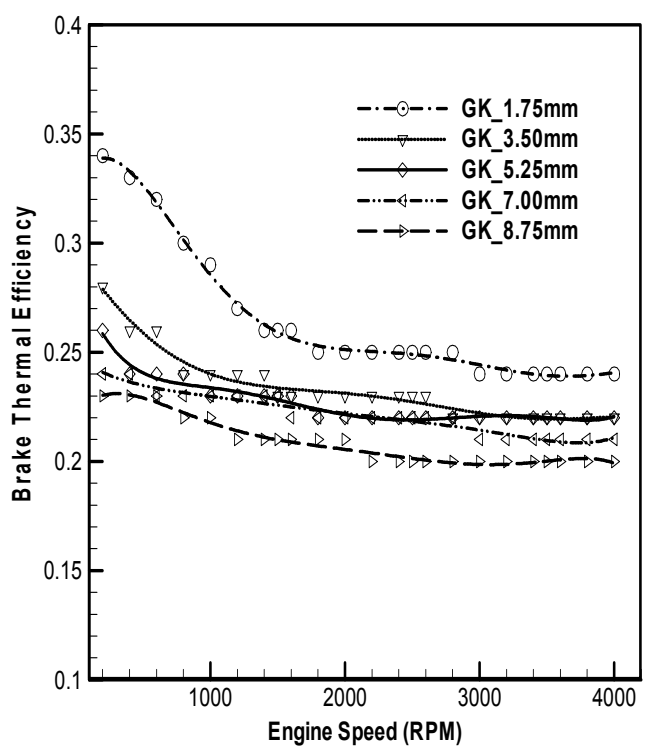

Figure 3: Effect of Speed on Brake Thermal Efficiency.

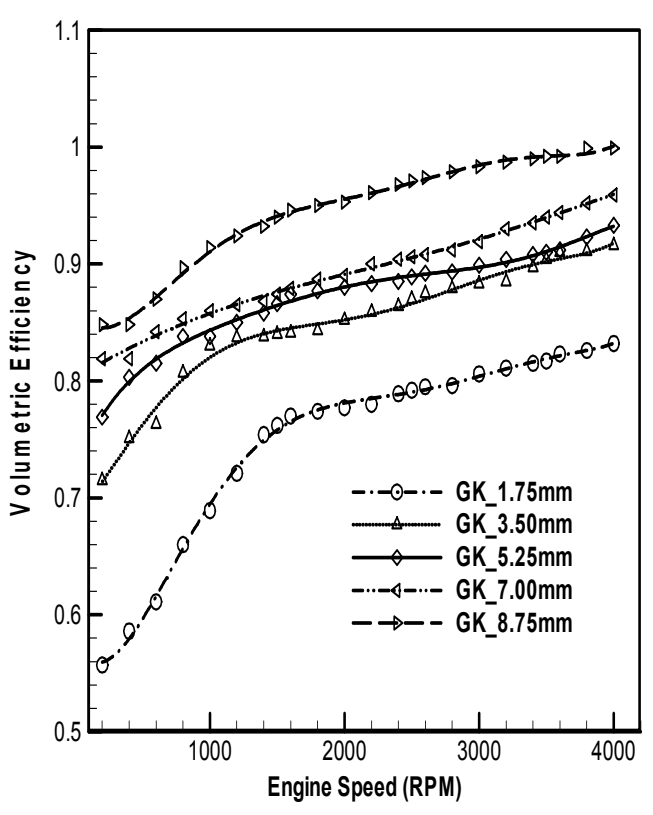

Figure 4: Effect of Speed on Volumetric Efficiency.

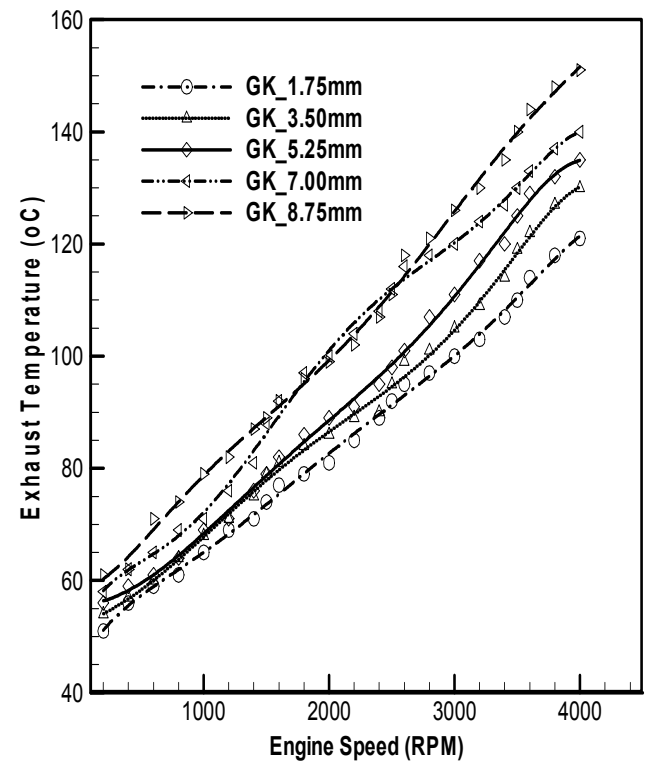

Figure 5: Effect of Speed on Exhaust Temperature

\section{CONCLUSION}

Increasing the gasket thickness has both favorable and adverse effect on the performance of the engine with the latter outweighing the former. Therefore, the most common misconception of having to select head gasket of thicker material is been laid to rest.

As discovered, the thicker the material, the more likely the material being contained can 'weep' through the pores of the gasket material, with possible different effect on some materials than the others. A rule of 
thumb is to have the material thick enough to compensate for any surface irregularities and to permit for some compression and necessary resiliency to seal the cylinder and sufficient thermal and chemical resistance required in the vicinity of the combustion chamber.

\section{REFERENCES}

Bickford, J. H., 1997. Gaskets and Gasketed Joints. CRC Press. 57pp.

Blackmore, D. R. and Thomas, A., 1977. Fuel Economy of the Gasoline Engine, New York, NY: John Wiley \& Sons.

Daniels, C. C. and Braun, M. J., 2006. The friction behavior of individual components of an SI engine during warm-up. Tribology Transactions 49(2):166-173.

Eastwood, P., 2000. Critical Topics in Exhaust Gas after-Treatment. Research Studies Press Ltd.

Hosseini, S., Abdolah, R., and Khani, A., 2008. A developed quasi-dimensional combustion model in SI Engines. Proceedings of the World Congress on Engineering 2008 Vol. II WCE 2008, July 2 - 4, 2008, London, U.K.

Johnson, J. H., 2005. Combustion and emission control for SI engines; modeling and experimental studies, A collection of SAE technical papers.

Kahraman, N., Çeper, B., Akansu, O. and Aydin, K., 2009. Investigation of combustion characteristics and emissions in a spark-ignition engine fuelled with natural gas-hydrogen blends. International Journal of Hydrogen Energy 34 (2): 1026-1034.

Karlowitz, B., 1974. Method for Emission Control for Spark Ignition Engines.
Kataoka, K, Tsurusaki, M. and Kadota, T., 2005. Effect of fuel properties on the combustion process and nitric oxide emission in spark ignition engine. SAE International.

Kunihiko, S., Taizo, M., Mamoru, N. and Kenichi, M., 2005. Optimum control of SI timing in a gasoline engine using model based methodology. Proceedings of JSAE Annual Congress 107(5): 5-8.

Liberman, M. A., 2008. Introduction to Physics and Chemistry of Combustion. Springer-Verlag Berlin Heidelberg.

Maus, W., Brück, R., and Holy, G., 1999. Future exhaust-gas after-treatment technologies for $\mathrm{SI}$ Engines. The next generation of super ultra low emission vehicles, engine \& environment pollutant emissions versus $\mathrm{CO}_{2}$. International Congress in Graz, September 2 - 3.

Morel, T., Lohmann, R. P. and Rackley, J. M., 1981. Fluid mechanics of combustion systems. Proceedings of the fluid engineering conference Boulder, Co, June 22-23.

Nunney, M. J., 1998. Light \& Heavy Vehicle Technology, Elsevier. Pp23.

Nunney, M. J., 1974. The Automotive Engine, London: Newnes-Butterworths.

Owen, K. and Coley, T., 1990. Automotive Fuels Handbook. Warrendale PA: Society of Automotive Engineers.

Skjoedt, M., Butts, R., Assanis, D. N. and Bohac, S. V., 2008. Effects of oil properties on spark-ignition gasoline engine friction. Tribology International 41(6): 556-563. 